\title{
The Breakthrough Series Collaborative on Service Integration: A Mixed Methods Study of a Strengths-Based Initiative
}

\author{
Cynthia A. Lietz \\ Kathleen L. Andereck \\ Richard C. Knopf
}

\begin{abstract}
Arizona's Department of Economic Security (DES) engaged in a strengthsbased initiative to increase quality and integration of human services. Twenty teams including employees from state agencies, community leaders, and families were brought together to discuss and implement improvements to a variety of social services. A mixed methods study was conducted to explore the complex process of forming diverse teams to strengthen social services. Specifically, the research team conducted focus groups to collect qualitative data from a purposive sample of the teams to explore their experiences in greater depth. Analysis of the data led to the development of an online survey instrument that allowed all collaborative members an opportunity to participate in the study. Findings suggest that while the teams faced many challenges, a commitment to the process brought perseverance, communication, and creativity allowing this collaborative to initiate 105 activities to bring about positive changes in social services within their communities.
\end{abstract}

Keywords: Strengths perspective, service integration, mixed methods, family voice

\section{INTRODUCTION}

The issues facing families are complex. Problems such as poverty, child maltreatment, delinquency and crime affect the safety of our communities, the stability of our families, and can have negative effects on the growth and development of children. As states seek to respond to these challenges, many recognize the need to increase communication and collaboration between service providers while also seeking involvement of families in the planning and decision making process. Arizona's Department of Economic Security (DES) engaged in a year-long initiative known as the Breakthrough Series Collaborative on Service Integration (BSCSI). This effort brought together agency staff from multiple DES programs and community leaders from social service agencies with service recipients to form 20 teams across Arizona for the purpose of better addressing the complex needs of families. The purpose of this article is to present the findings from a mixed methods study that explored this collaborative process to identify both the challenges and advantages of this approach to social work practice.

\section{Social Work Practice with Families}

Some claim that social work practice with children and families developed from a deficits-based model seeking to diagnose problems and provide treatment to ameliorate

Cynthia A. Lietz, Ph.D., is an Assistant Professor in the School of Social Work, Kathleen L. Andereck, Ph.D., is Professor and Director, School of Community Resources and Development, and Richard C. Knopf, Ph.D., is Professor and Director, Partnership for Community Development, School of Community Resources and Development, all in the College of Public Programs at Arizona State University in Phoenix. This research was funded by the Arizona Department of Economic Security. The authors are grateful for the support and guidance of the Office of Community Partnerships and Innovative Practices (CPIP). 
symptoms (Early \& GlenMaye, 2000; Itzhaky \& Bustin, 2002; Leon, 1999; Saleebey, 2001). Chapin (1995) asserts public policies stemmed from a similar perspective with an emphasis on the identification of societal problems focused on minimizing factors found to increase risk for dysfunction. Practitioners within social service programs responded by adopting diagnostic terminology that would aid those engaged in the helping professions to identify pathology by attaching a label to particular behaviors or experiences ultimately leading to a prescribed treatment (Leon, 1999).

Over time, many have critiqued social work's adoption of the medical model due to the overemphasis on diagnosis and treatment of problems (Blundo; 2001; Goldstein, 1997; Leon, 1999; Lietz, 2006; Saleebey, 2001). Saleebey (2006) asserts that overattention to deficits hinders a social worker from seeing the strengths and capabilities of an individual, family, or community. Others suggest the medical model does not fit social work's value of collaboration as this perspective creates a hierarchy reinforcing the idea that professional social workers hold the expertise to assess and treat pathology, potentially hindering the voice of families (Itzhaky \& Bustin, 2002; Weick, Rapp, Sullivan, \& Kisthardt, 1989). Still others cite concerns regarding the language of pathology that fails to empower clients to see their abilities, to reflect on past successes, and to foster resilience (Goldstein, 1997; Greene, Lee, \& Hoffpauir, 2005).

Proponents of the strengths perspective seek to shift focus away from problems to instead emphasize the inherent strengths that are present in all people, families, and communities (Blundo, 2001; Brun \& Rapp, 2001; Cohen, 1999; Kisthardt, 2006; Saleebey, 2006). The language of the strengths perspective includes concepts such as membership, wellness, resilience, and hope, seeking to replace words that draw attention to pathology with ones that empower people to see their capabilities (Greene et al., 2005; Rapp, Saleebey \& Sullivan, 2005). Social workers engaging in strengths-based practice develop collaborative relationships that acknowledge the expertise of families and communities in knowing what works best when addressing the problems families face (Boyes-Watson, 2005; Colby, 1997). The dialogue and collaboration between family and worker seek to highlight abilities, resources, and past successes to accomplish current goals identified by the family (Sousa, Ribeiro, \& Rodrigues, 2006). In addition to collaboration between families and workers, we argue that the strengths perspective also highlights a need for communication between service providers and an enhanced integration of services. Critical to this perspective is the idea of partnering with families and communities in a way that raises their voice in the discourse about intervention and integration of social services (Boyes-Watson, 2005; Brun \& Rapp, 2001; Colby, 1997; Leon, 1999).

Critics of the strengths perspective claim this practice philosophy simply attempts to reframe problems and fails to acknowledge the real problems that families face (Saleebey, 2006). According to recent data from the National Child Abuse and Neglect Data System (U.S. Department of Health and Human Services, 2007), almost 900,000 children were found to be victims of abuse or neglect in 2005. This suggests that 12 of every 1,000 children in the U.S. face maltreatment. Findings reported by the Annie E. Casey Foundation (AECF) (2007) suggest that 1.1 million teens were not in school and did not have high school diplomas in 2003. That same year, the drop-out rate for minority 
groups ranged from 8 to 15\% (AECF, 2007). Other data suggest that one in five American children live in poverty while many live just above the poverty line (AECF, 2007). American families face many challenges of concern to the field of social work and to public policy makers.

Those who advocate for taking a strengths perspective do not claim the real challenges families face are ignored. Nor do they suggest that children are not heard as they speak of maltreatment or that parents struggling to care for their family are not provided with support needed to meet basic needs. On the contrary, proponents of the strengths perspective care deeply about these concerns. What makes the strengths perspective different is not the concern for the well-being of children and families, but instead, the approach taken as social workers address these issues.

\section{Service Integration}

As local governments seek to provide for the needs of their communities, one effort that has gained attention is the strategy of service integration. Hassett and Austin (1997) define service integration (SI) as "efforts to reduce or eliminate divisions or boundaries between categorically defined and provided services” (p. 10). Similarly, O’Looney (1994) describes SI as "specific changes believed to make the system more efficient, effective and comprehensive” (p. 32). The strategy of service integration seeks to make improvements to social services that have been found to be fragmented, uncoordinated, inflexible, and confusing (O’Looney, 1994; Reitan, 1998; Waldfogel, 1997). Some believe these problems stem from specialization within social services requiring one family to be referred to multiple agencies to meet a variety of needs (Leon, 1999; O’Looney, 1997). In a system divided through specialized expertise, there may be little communication between service providers, causing families to feel like they are starting over with each new referral.

Although the SI movement can be traced back to the mid 1900s, there was a renewed interest in this practice in the late eighties and early nineties (Hassett \& Austin, 1997; O'Looney, 1997). Currently, there are examples of SI initiatives in several states including Georgia, California, Kentucky (O’Looney, 1997), Maryland, Colorado (Waldfogel, 1997), and Arizona. Hassett and Austin (1997) describe mixed motivations for SI efforts. Client advocates see integration as an opportunity to provide more comprehensive and effective services to families. Agency administrators and governmental leaders may look to SI as a more efficient and cost-effective way to provide services.

In addition to mixed motivations for employing SI practices, there are other factors complicating implementation. For example, Halley (1997) states "SI has been characterized as lacking crisp language, being, at once, a philosophy, an objective and a set of strategies and structural arrangements” (p. 146). Lack of clarity and direction may affect the effectiveness of such initiatives. In addition, O’Looney (1997) suggests implementing SI is limited by a lack of current research informing this practice. It appears that further development of the idea of SI along with research findings may be needed to better inform future efforts. 


\section{Arizona's Breakthrough Series Collaborative on Service Integration (BSCSI)}

In 2003, social service leaders in Arizona were concerned regarding the number of families who were living in poverty, involved with the child welfare system, and at-risk for inadequate housing, nutrition, and healthcare. DES leaders desired to increase access and coordination of social services in an effort to better address these issues. DES approached the Annie E. Casey Foundation regarding implementing the Breakthrough Series Collaborative (BSC) model as a way of implementing responsive, creative solutions to these complex social problems. Through financial and technical support provided by the Casey Foundation, a planning team was put in place to: (a) form a collaborative of 20 teams for the purpose of increasing service coordination and efficiency, (b) plan the learning summits needed to train and support teams in the BSC process of change adopted for this project, and (c) offer general oversight to the project.

The planning team asked each division within DES to nominate members who were ultimately assigned to one of the 20 teams located in their geographical area. The collaborative brought together groups of people representing three interests. Under the umbrella of Arizona's DES, there are many social services including the administration of programs to address child maltreatment, financial need, and child support. Each BSCSI team was formed through nominations of representatives assigned from each division of DES. In addition to DES professionals, each division nominated community leaders who were involved in each local area who were also invited to serve on a BSCSI team. These BSCSI participants could be administrators or practitioners from non-profit agencies, pastors or elders from faith institutions, or other community members concerned with social services. Finally, each team also recruited family members to bring the important perspective of service recipients. Brun and Rapp (2001) conclude "proponents of the strengths perspective risk being one of the oppressors themselves if they do not systematically and consistently seek the opinions of individuals receiving strengths-based services” (p. 279). Understanding the collaborative could not adequately address social service issues without hearing directly from recipients; a key priority was the recruitment of family partners. Ultimately, throughout this year-long effort, the collaborative included the participation of 93 family partners, 107 community partners, and 118 DES partners who were assigned to one of 20 local teams.

The entire collaborative came together at the first learning summit in January of 2006. At this meeting, teams were formed and oriented to their purpose. The purpose of each team was to identify barriers to services and to explore creative actions that could lead to increased integration of services in each community. Specifically, each BSCSI team was trained in the Plan, Do, Study, Act (PDSA) process (Deming, 1986) for initiating small tests of change that can be spread across to other communities and, ultimately, across the state. Teams met locally each month to identify creative ways to strengthen social services for a period of one year. Two additional learning summits were held with the entire collaborative in May and October of 2006 to provide further support to the teams.

The goal of service integration through collaborative processes fits SI practices. One unique aspect of this SI initiative was the deliberate attention paid to engaging families 
on each BSCSI team. Although there are several principles underlying the strengths perspective, "the first is a belief that people have the capacity to determine what is best for them" (Weick et al., 1989, p. 353). Colby (1997) suggests "a community must have ownership of the project” (p. 9), while Chapin (1995) similarly concludes "social policy that reflects the reality of its intended recipients is more likely if the policymakers are also the people directly affected by the policy” (p. 509). We contend that bringing the strengths of professionals, community leaders, and families together through collaboration for the purpose of seeking creative solutions provides an illustration of a strengths-based, community initiative on service integration.

\section{METHODS}

Arizona State University's Partnership for Community Development (PCD) was approached to conduct a study to examine the process of the BSCSI. The research team utilized a combination of quantitative and qualitative methods through a sequential exploratory design (Creswell, 2003) to understand the functioning of these teams. Specifically, the research team initially collected qualitative data through focus groups conducted with 13 of the 20 BSCSI teams. An analysis of this data suggested the qualitative sample cited strengths and barriers related to the functioning of their teams. This qualitative analysis was used to develop a survey instrument with closed-ended items to further test the variables identified in the focus groups. This survey was sent to the entire collaborative, allowing all members the opportunity to participate in at least one component of this study. The study was approved and monitored by ASU's Institutional Review Board.

\section{Qualitative Methods}

The qualitative component of the research was used to examine the experiences of the teams in greater depth. The researchers used purposive sampling to identify 13 of the 20 teams to participate in the qualitative component of the study. Specifically, the researchers desired to seek a sample of teams that represented diversity across the collaborative. Therefore, rather than choosing a random sample of teams, teams were chosen from all geographic locations across the state leading to an oversampling of rural areas. Specifically, six teams representing metropolitan areas in Phoenix and Tucson were included whereas the other seven teams came from locations across Arizona. A semi-structured interview guide provided in Table 1 was used to conduct focus groups with each team to explore their perceptions regarding the purpose of the collaborative, the functioning of the teams, and the effectiveness of their efforts to initiate change.

The focus groups were co-facilitated by two members of a team of five researchers. The team included the Principal Investigator (PI) of the qualitative component of the project and four masters level social work research assistants (RA) who were trained and supervised by the primary researcher. Consistency in facilitation was established through: (1) an initial training provided by the PI for all of the RAs, (2) weekly RA supervision meetings led by the PI, (3) attendance of RAs at two focus groups facilitated by the PI for the purpose of modeling facilitation, and (4) the use of an interview guide. 
Table 1: $\quad$ Interview Guide

1. What led you to become involved in this team?

2. What about being on this team have you enjoyed?

3. Were there any barriers that made it difficult for you or someone else to participate fully on this team?

4. What do you see as the purpose of this team?

5. In what ways has your work as a team led to improved services for families in AZ?

6. Can you share a few examples of how your work in this team has led to improved outcomes for a family?

7. If the Breakthrough Series is to continue successfully, what do you think needs to happen to move forward?

The focus groups ranged in length from 50 to 120 minutes and were audio-taped and transcribed to prepare for analysis. Ultimately, of the 318 registered collaborative members, 97 participated in one of the 13 focus groups. Important to note is that not all 318 people who were registered as collaborative members were actively participating at the point of the study. This sampling frame includes any person who attended a meeting at any time, even if that person only attended one meeting or event. Although exact numbers are not available, leaders of the collaborative estimate that the number of active participants ranged from approximately 150 to 200 at the point of the study. Therefore, this suggests the 97 qualitative participants represent about half of the active collaborative members.

To analyze the qualitative data, the research analysts used both open and theoretical coding as described by Coleman and Unrau (2008). Open coding involved a team of five analysts reading the transcripts for common words or ideas that were expressed. Based on this initial reading, master codes were identified leading to the development of a protocol used for secondary coding. The analysts used the protocol to go back into the data and code each meaning unit according to the codes established through the initial analysis. All quotes assigned to each code were integrated allowing for an in depth vertical analysis of all meaning units contained within each theme. Additionally, horizontal analysis was conducted that involved looking at relationships across themes. The findings were ultimately reconstructed and presented to the collaborative at the final BSCSI summit.

The qualitative research team used various strategies to increase the trustworthiness of the findings. First, triangulation by observer (Padgett, 2008) was used such that five researchers were involved in data analysis to increase the likelihood that important perspectives on the data were not missed. Additionally, reflexivity, a thoughtful consideration of one's effect on the research process (Horsburgh, 2003), was used. 
Specifically, the team met before analysis to identify preconceived notions regarding service integration and the BSCSI project. The team also met twice during data analysis to reflect on how social location could affect the data analysis process. Finally, although member checking was not conducted, the PI presented the findings to the entire collaborative at their final learning summit. Anecdotally, several professional, community, and family partners approached this researcher at the end of this presentation and reported the findings captured their experiences. As of result of these efforts and this informal feedback, we believe we increased the confidence that these findings represent a trustworthy portrayal of the data.

\section{Quantitative Methods}

Once the qualitative researchers completed their analysis, the prevailing themes were identified and used to develop a quantitative instrument to test these findings with a larger sample of the collaborative. Specifically, the quantitative component of the BSCSI evaluation consisted of an instrument developed by the survey team and administered online or by mail. The evaluation consisted of several sections measuring a series of variables. The survey measured (a) the perceived level of functioning of the community teams, (b) the extent to which participants felt the work of their team was effective, and (c) the perceived barriers to effectiveness.

All of the following groups of items were derived from the focus groups' results. Nine items asked the extent to which team members felt characteristics related to successful team outcomes were descriptive of their teams. These were measured on a five-point scale ranging from "strongly disagree" to "strongly agree." Five items were asked regarding the extent to which team members felt various actions related to successful team outcomes were descriptive of their teams. These were measured on a five-point scale ranging from "not helpful" to "extremely helpful." Twelve items were asked regarding the extent to which team members felt various problems created barriers to achieving successful team outcomes. These were measured on a five-point scale ranging from "strongly disagree" to "strongly agree."

The next variables incorporated into the survey related to the experiences respondents had with their teams. They were asked questions regarding the formats for their meetings and the level of participation of different types of team members. They were then asked to respond to several questions related to their experiences with the team measured on a five point scale ranging from "strongly disagree" to "strongly agree." These questions were drawn from Krile (2006). Finally, they were asked to provide an overall satisfaction assessment of their team's progress (five-point scale where $1=$ not satisfied and $5=$ extremely satisfied).

The instrument was sent or made available to all team members generally following Dillman's (2007) approach. Team members were first sent an email message from BSCSI staff letting them know the study would be conducted and encouraging their participation. They were then sent an email message with a link to the web-based survey by the researchers. This was followed by two email message reminders several days after the original message. For team members with no email address, essentially the same 
procedure was followed by mail, with a cover letter, paper evaluation, and postage paid reply envelope sent initially and postcard reminders sent later. A total of 315 team members (contact information for three participants was not available) were contacted by email or mail to complete the questionnaire with 145 responses for a response rate of $46 \%$. The demographic profile of survey respondents is included in Table 2.

Table 2: $\quad$ Demographic Characteristics of Survey Respondents (N=145)

\begin{tabular}{|c|c|c|}
\hline Characteristics & Frequency & Percentage \\
\hline \multicolumn{3}{|l|}{ Gender } \\
\hline Female & 92 & 78.6 \\
\hline Male & 25 & 21.4 \\
\hline \multicolumn{3}{|l|}{ Age $($ mean $=48.6)$} \\
\hline $24-39$ & 19 & 17.6 \\
\hline $40-49$ & 39 & 36.1 \\
\hline $50-59$ & 38 & 35.2 \\
\hline $60+$ & 12 & 11.1 \\
\hline \multicolumn{3}{|l|}{ Education } \\
\hline Less than high school & 1 & 0.9 \\
\hline High school diploma & 7 & 6.1 \\
\hline Some college & 37 & 32.2 \\
\hline Two year college degree & 21 & 18.3 \\
\hline Four year college degree & 34 & 29.6 \\
\hline Advanced degree & 15 & 13.0 \\
\hline \multicolumn{3}{|l|}{ Annual income } \\
\hline$\$ 20,000$ or less & 6 & 5.4 \\
\hline$\$ 20,001-40,000$ & 38 & 34.2 \\
\hline$\$ 40,001-60,000$ & 33 & 29.7 \\
\hline$\$ 60,001-80,000$ & 14 & 12.6 \\
\hline$\$ 80,001+$ & 20 & 18.0 \\
\hline \multicolumn{3}{|l|}{ Race/Ethnicity } \\
\hline Caucasian & 66 & 57.9 \\
\hline Latino & 34 & 29.8 \\
\hline American Indian & 9 & 7.9 \\
\hline African American & 4 & 3.5 \\
\hline Other & 4 & 2.7 \\
\hline \multicolumn{3}{|l|}{ Type of participant } \\
\hline Family partner & 13 & 11.0 \\
\hline DES partner & 72 & 61.0 \\
\hline Community partner & 33 & 28.0 \\
\hline
\end{tabular}




\section{FINDINGS}

The qualitative data analysis led to the identification of three themes each explained by a set of sub-codes. Specifically, when describing their experiences with the BSCSI, findings suggest participants in this research: (1) experienced a series of barriers to their efforts, (2) demonstrated a sincere commitment to the principles of service integration, and (3) relied on strengths to overcome challenges to achieve positive outcomes. These findings were supported by the responses on the quantitative instrument as well.

\section{Barriers and Challenges}

As team members discussed their experiences, three barriers were consistently identified: (a) confusion regarding roles and purpose, (b) lack of support from the larger social service system, and (c) difficulty maintaining and recruiting family partners.

Table 3: $\quad$ Barriers Experienced by Team Members

\begin{tabular}{|c|c|c|c|c|c|c|}
\hline \multirow[b]{2}{*}{ Barriers } & \multicolumn{5}{|c|}{ Percents } & \multirow[b]{2}{*}{ Mean } \\
\hline & $\begin{array}{l}\text { Strongly } \\
\text { disagree }\end{array}$ & Disagree & Neither & Agree & $\begin{array}{l}\text { Strongly } \\
\text { agree }\end{array}$ & \\
\hline $\begin{array}{l}\text { Confusion about who was in charge } \\
\text { of the team }\end{array}$ & 10.9 & 34.0 & 20.4 & 20.4 & 12.9 & 2.9 \\
\hline $\begin{array}{l}\text { Confusion about the purpose of the } \\
\text { project }\end{array}$ & 4.8 & 21.8 & 20.4 & 34.7 & 17.0 & 3.4 \\
\hline $\begin{array}{l}\text { Lack of knowledge about the project } \\
\text { by the larger DES community }\end{array}$ & 1.4 & 13.6 & 14.3 & 32.7 & 36.1 & 3.9 \\
\hline Not feeling that the team was valued & 8.8 & 27.2 & 29.3 & 20.4 & 12.9 & 3.0 \\
\hline $\begin{array}{l}\text { Lack of resources needed to } \\
\text { implement actions }\end{array}$ & 2.7 & 15.0 & 20.4 & 32.7 & 27.2 & 3.7 \\
\hline $\begin{array}{l}\text { Lack of authority to implement } \\
\text { actions }\end{array}$ & 5.4 & 13.6 & 21.8 & 25.9 & 32.0 & 3.7 \\
\hline Difficulty engaging family partners & 0.7 & 10.2 & 12.9 & 25.2 & 49.7 & 4.1 \\
\hline People moving in and out of the team & 1.4 & 8.2 & 12.9 & 42.2 & 32.0 & 4.0 \\
\hline Took a while to get started & 1.4 & 19.7 & 15.6 & 36.1 & 25.9 & 3.7 \\
\hline $\begin{array}{l}\text { Establishing team cohesiveness took } \\
\text { some time }\end{array}$ & 1.4 & 21.1 & 14.3 & 42.9 & 19.0 & 3.6 \\
\hline Extranet/computer problems & 3.4 & 16.3 & 27.9 & 22.4 & 27.2 & 3.6 \\
\hline Overly complex process & 2.7 & 21.8 & 25.9 & 28.6 & 19.7 & 3.4 \\
\hline
\end{tabular}


Confusion regarding roles and purpose. Several participants discussed facing confusion early on in the project regarding their purpose. One community partner stated, "I think in the beginning people didn’t know which way they were going and what was their role" while a DES partner stated, "I think a lot of it early on was confusion. We were spinning our wheels a lot at the beginning." Some DES partners thought they were required to participate in the collaborative despite contrary communication suggesting involvement was to be voluntary. Family and community partners also expressed a lack of clarity regarding their purpose and role. This issue was also noted by respondents to the survey (Table 3). A number of participants agreed that there was a lack of clarity regarding the purpose, and some noted confusion about who was in charge of the team. When asked about actions that could have helped, nearly all indicated that increased clarity of the project and process would have been at least moderately helpful (Table 4).

Table 4: $\quad$ Support for Teams

\begin{tabular}{lccccc}
\hline & \multicolumn{5}{c}{ Percents } \\
\cline { 2 - 4 } & Not helpful & $\begin{array}{c}\text { Slightly } \\
\text { helpful }\end{array}$ & $\begin{array}{c}\text { Moderately } \\
\text { helpful }\end{array}$ & $\begin{array}{c}\text { Very } \\
\text { helpful }\end{array}$ & Mean \\
\hline $\begin{array}{l}\text { Increase clarity of the project and } \\
\text { process }\end{array}$ & 2.0 & 9.5 & 35.4 & 51.7 & 3.4 \\
$\begin{array}{l}\text { Increase knowledge about this } \\
\text { project relative to the larger DES }\end{array}$ & 1.4 & 7.5 & 33.3 & 56.5 & 3.5 \\
$\begin{array}{l}\text { system } \\
\begin{array}{l}\text { Increase acknowledgment and } \\
\text { encouragement for the teams }\end{array}\end{array}$ & 2.7 & 19.0 & 32.0 & 43.5 & 3.2 \\
$\begin{array}{l}\text { Provide incentives for family partner } \\
\text { participation }\end{array}$ & 1.4 & 14.3 & 24.5 & 57.8 & 3.4 \\
$\begin{array}{l}\text { Support from DES for engaging } \\
\text { more family partners }\end{array}$ & 4.8 & 10.9 & 27.2 & 55.1 & 3.4 \\
\hline
\end{tabular}

Lack of support from the social service system. DES partners and some of the community and family partners discussed experiencing a lack of support from the larger social service system as one significant barrier to the work of their BSCSI team. Lack of support was perceived by these participants in different ways. Some team members who were social service professionals felt their supervisors did not support their participation in the collaborative, they received criticism for time spent away from their jobs, and they did not receive workload reduction for the time spent on BSCSI activities. One team member stated, "There's no buy in from supervisors." In addition, many felt administration did not support the work of the BSCSI teams. One community partner stated, "We could not get our ideas approved" while another partner stated, "The larger system has not bought into the service integration philosophy creating resistance to the ideas generated through PDSAs.” Survey participants reported these types of barriers as 
well. Most felt that the larger DES community was not knowledgeable about the project (Table 3) and that increased knowledge about the project would have been at least moderately helpful (Table 4). They also felt the teams did not have the resources or the authority to implement actions (Table 3). The respondents tended to be split between agreeing and disagreeing that their team was valued, and a large percentage (76\%) felt that more acknowledgement and encouragement for the teams would have been helpful (Tables 3 and 4).

Difficulty maintaining and recruiting family partners. All the teams we spoke to expressed a clear commitment to incorporate family and community voice on these teams. When family and community voice was included, the teams clearly saw the benefit. They reported increased insight and understanding regarding how to improve services for families. At the same time, all but two teams discussed significant difficulty maintaining family voice on their teams. The teams reported that some families would verbally commit to attendance but then not show up for meetings. When they did come, attendance was inconsistent making it difficult to fully engage family partners in the process. One DES partner explained, "Our biggest challenge was keeping the family partners. Although initially we had three family partners that were involved and interested and excited, one by one other things in their lives took priority, and they became less interested in us." Teams discussed conflicts in scheduling meetings and events as families needed evening or weekend meetings while DES partners and many community partners preferred day events. Many teams were quite creative and diligent in their attempts to accommodate and engage family partners. However, when changes were made to accommodate families, sometimes families would not attend and the teams would also lose DES and community participation as a result of changing the meeting time. All teams reported a desire for further education and support regarding this barrier. The concern regarding including family members was clearly reiterated in the quantitative results. Over $75 \%$ of respondents agreed that difficulty engaging family partners was a barrier (Table 3) and nearly all felt that incentives and additional support from DES would have helped in engaging family partners (Table 4).

\section{Commitment to the Service Integration Philosophy}

Findings suggest the BSCSI teams experienced many barriers to their efforts ranging from confusion regarding their roles or purpose, difficulty retaining family partners along with a perceived lack of support and time constraints. Considering these struggles, one might expect that some of the teams would not have made it through the full year of this project. Yet, as the research team examined the experiences of the collaborative, we discovered that all teams were still meeting, pursuing small tests of change through the PDSA process and making improvements in services in their communities. As we pondered this finding, we identified many statements in our interviews that were coded as "commitment" that explained why the teams kept going despite the struggles they faced. This finding was also apparent in the survey results with $75 \%$ reporting agreement to a commitment to the philosophy of the program (Table 5). 
Table 5: $\quad$ Characteristics of Successful Teams

\begin{tabular}{lccccccc}
\hline & \multicolumn{5}{c}{ Percents } \\
\cline { 2 - 5 } & $\begin{array}{l}\text { Strongly } \\
\text { disagree }\end{array}$ & Disagree & Neither & Agree & $\begin{array}{c}\text { Strongly } \\
\text { agree }\end{array}$ & Means \\
\hline $\begin{array}{l}\text { Commitment to the philosophy of the } \\
\text { program }\end{array}$ & 2.0 & 4.1 & 17.0 & 49.0 & 26.5 & 4.0 \\
$\begin{array}{l}\text { Strong participation by family } \\
\text { partners }\end{array}$ & 17.7 & 22.4 & 16.3 & 27.2 & 15.6 & 3.0 \\
$\begin{array}{l}\text { Strong participation by community } \\
\text { partners }\end{array}$ & 4.1 & 16.3 & 11.6 & 40.8 & 26.5 & 3.7 \\
$\begin{array}{l}\text { Diverse knowledge and experience } \\
\text { represented on the team }\end{array}$ & 0.7 & 1.4 & 4.8 & 52.4 & 40.1 & 4.3 \\
$\begin{array}{l}\text { Strong leadership for the team } \\
\begin{array}{l}\text { Good relationships among team } \\
\text { members }\end{array}\end{array}$ & 0.7 & 11.6 & 22.4 & 38.1 & 25.9 & 3.8 \\
$\begin{array}{l}\text { Having fun during meetings } \\
\begin{array}{l}\text { Maintaining flexibility during the } \\
\text { process }\end{array}\end{array}$ & 2.0 & 2.0 & 8.8 & 51.7 & 34.7 & 4.2 \\
\begin{tabular}{l} 
Demonstrating innovation \\
\hline
\end{tabular} & 2.7 & 4.8 & 15.0 & 46.3 & 31.3 & 4.0 \\
\hline
\end{tabular}

Many reported that as the year progressed, some of the original participants left and the remaining partners were the ones most committed to the philosophy. The teams may be smaller, but in some ways, became stronger through their shared commitment. Demonstrating this commitment, one DES partner reported:

In the past, it's always been DES making decisions and never hearing the voice of DES customers. Finally, that's changed and through the Breakthrough Series this is happening. So that's a good thing! It's been a really good experience.

Similarly, a family partner stated, "I saw all these people in one room saying we can make difference, we want to understand what it's like. I want to be a part of that so bad! I want to be a part of change!” Our research team observed members committed to the project, who desired for this philosophy to continue such that services would be improved through service integration.

In addition to demonstrating a commitment toward service integration, participants consistently spoke of their desire to incorporate family voice in social service delivery. One DES partner illustrated this commitment stating, "This is the first time we have listened to families. DES has always made the decisions, it didn't matter what anybody else thought. Now, the roles are kind of reversed, and it's really having a good impact for 
the customers." Similarly, one community partner concluded, "We wouldn't even know some things are problems without hearing it from our families." DES and community partners consistently discussed the insight gained from the involvement of families.

Along with increased insight, many partners also discussed how their motivation elevated when they saw the impact of their work first hand. For example, one DES partner talked about a renewed passion for her job. She stated:

I stick with this because my families are benefiting from it. So, it makes me more professional as a social worker, and it makes me fall in love with my job more and with other people with the same passion and purpose.

DES and community partners reported many intrinsic benefits of collaborating with families on their BSCSI teams. One striking finding related to family voice was the benefits identified by the family partners themselves. While family voice brought insight to social service workers, families also came to understand more about the perspective of the worker through their involvement in the BSCSI. For example, one family partner shared:

Being part of the Breakthrough Series, I get to see them actually doing their job and I see the passion. I have something to offer, because I have been through it. But, they are not just learning what it's like to be on my side. I am also learning what it is like for them. Everyone has been learning.

In addition to increased insight, family members also developed self-esteem as they were involved in the BSCSI. One family partner stated:

When she asked me to participate, I just burst into tears, I was just so excited. Just the fact that she would ask me to participate in something to help other people showed that she did have faith in me. It gave me what I needed to continue in my sobriety. If I didn't have the Breakthrough Series to be involved in, I don't know where I would be.

Another family partner stated, "Being a part of the Breakthrough Series changed my life. Before I was nobody, now I am somebody.”

\section{Overcoming Barriers and Challenges}

As the teams discussed overcoming the challenges, it was clear that their commitment to the service integration philosophy and their desire "to make a difference" allowed them to move forward. In addition to this commitment, the teams described several strengths that helped support them as they sought to overcome these barriers. A spirit of perseverance fueled by a sense of hope, collaboration and communication, effective leadership, and relationship building helped these teams to persevere despite these struggles.

A spirit of perseverance driven by a sense of hope. As participants discussed barriers they faced during their involvement in this collaborative, our research team observed a spirit of perseverance that defined the character of these teams. As these BSCSI teams identified obstacles, they also discussed many strategies used to overcome 
these struggles. Collaborative members used phrases like “we just wouldn't give up” and we "stuck with it" illustrating this spirit. One DES partner illustrated this point stating, "We've had a lot of barriers, but, I am really proud of the team members because they've stuck through it all. We kept trying and trying and trying." These teams simply would not give up. Along with a spirit of perseverance, the research team also identified a sense of hope woven throughout much of our conversation. One family partner stated, "Being involved in the BSC gives me more hope for the future" while a DES partner shared, "What we did for families gave me a ray of sunshine, of hope, that we're moving in the right direction." When asked about his involvement in the collaborative, one community member responded, "What keeps me coming back? Hope. Hope that whatever services we're providing can help and we're united by that one goal." As these teams talked about their work with the collaborative, they asserted their belief that they could make a difference. It appeared as if they looked past obstacles in order to see the possibilities. The findings suggest perseverance was realized for teams through a pervasive sense of hope.

Collaboration and communication. In addition to their spirit of perseverance and a sense of hope, these teams consistently talked about the importance of collaboration and communication in their process. How did they overcome the barriers they faced? Put simply, they worked together. The ability to bring partners together coming from diverse experiences and backgrounds allowed these teams to understand the problems in a new way. Having multiple perspectives allowed the teams to identify more creative solutions. Working together and talking things out appeared to help these teams overcome obstacles leading to improved outcomes. One DES partner asserted this idea stating, "We worked together, discussing issues and how can we resolve it, and how we can help one another. I felt that a collaborative spirit was there.” Another DES partner summed up this point stating, "DES can't do it alone. Community partners can't do it alone. Family partners can't do it alone. But, when we come together and work toward a common goal, that's the key!" Involvement by community members was an important aspect of successful teams according to survey respondents, however the challenges of participation by family members was once again evident (Table 5). Having multiple perspectives also allowed the teams to identify more creative solutions. This was strongly reiterated by survey respondents with 92\% agreeing that diverse knowledge and experience was a characteristic of a successful team (Table 5).

Effective leadership. One idea discussed by several participants of the BSCSI was coded as "leadership." Many teams who were pleased with the accomplishments of their team gave credit to team leaders for their ability to keep the team organized, on track and informed. One family partner discussed this concept stating, "I think leadership helps. He's got great leadership. Our team leader keeps us well informed. He keeps us involved.” Similarly, a DES partner stated, "Our leader has all the qualities to lead a team like this. I just wanted to recognize her as somebody who I have a lot of respect for, for not giving up and continuing to lead us," while another DES partner concluded, "I think our team leader is a wonderful example of someone who has the right attitude and personality to work with a diverse group of people like we have.” This qualitative finding 
was reemphasized in the survey in which $64 \%$ of respondents felt this was a characteristic of a successful team (Table 5).

Relationship building. Finally, one of the most consistent comments we heard during our time with BSCSI participants highlighted the importance of relationship building during this project. Words such as "bonds," "connections," and "friendships" were used when participants spoke about what helped their team succeed. Relationships were also identified as what many participants enjoyed most about being involved in the collaborative. Survey respondents echoed this sentiment noting that both good relationships among team members and having fun during meetings were hallmarks of successful teams (Table 5). One community member concluded, "It's the people that keep me coming back to this team. It's the heart they have for what they are doing." Similarly, one family partner explained, "There are lots of different personalities, different ways of doing things, but, still, the bond, the bond that we continue to create is there." The relationships that were formed on these teams allowed diverse groups of people to come together, identify commonalities and move forward in the work of their team.

\section{DISCUSSION}

There are limitations to this study. These findings are not generalizable, and data gained through focus groups may be hindered by social desirability. The additional quantitative data that was collected allowed all members of the collaborative to participate. However, there is no way to ascertain whether the $46 \%$ response rate may have represented many of the same people who participated in the focus groups. In addition, there was significant missing data in the quantitative survey, particularly for the demographic questions, another limitation of the study. Finally, this project focused on the process of the teams, not outcomes. We are unable to draw conclusions about the success of the efforts, but instead focused on the perceptions of the people most intimately involved in the work of this collaborative for the purpose of understanding more about the experiences of those involved in this initiative.

Despite these limitations, the data provide some important insights into the experiences of participants of this strengths-based initiative. Specifically, findings highlighted the challenges faced when collaborative teams are brought together for the purpose of improving services through integration. Confusion, lack of support, and practical issues such as scheduling conflicts made this task difficult. However, a striking finding was the commitment the remaining members of this collaborative maintained to the service integration philosophy and to their team approach. This commitment led to perseverance, increased communication, and relationship building to accomplish their goals. At the end of the project, teams were pleased with their progress and were able to cite specific examples regarding how their efforts translated into positive outcomes for families.

Specifically, the collaborative implemented 105 innovative strategies to improve social services, including procedures to increase community education and awareness of services, efforts to enhance efficiency of service delivery, and activities to improve 
customer service. For example, 19 efforts involved increasing access to services by developing service directories, improving telephone systems, and providing more accurate information in the lobbies of social service areas. Another 19 activities sought to increase efficiency by streamlining application procedures, creating new forms and case tracking processes, and implementing new ways of sharing information across the divisions within DES. Twenty-three of the strategies sought to increase communication between service providers and recipients by holding community forums and further exploring client satisfaction with services. Seven of the innovations related to education and training such as offering GED classes during both day and night hours, conducting prevention workshops for teens about dating violence, and providing job training for youth. Finally, 37 of the activities related to improving customer service and enhancing the physical environment of places at which services are delivered. For example, one team was able to solicit volunteer artists to paint a mural in a lobby, one team created a waiting area for children inclusive of toys and furniture appropriate for young children, and one team partnered with seniors to provide artwork in the waiting areas.

As the collaborative brought social service professionals, community leaders, and families together for the purpose of improving services in Arizona, it is important to note a few of the unexpected positive impacts that were also discussed by partners in this project. First, social workers identified a renewed passion for their jobs as they had the opportunity to sit at the table with families to improve services. As social workers came to see families not as clients, but as people seeking positive change for their communities, this commonality encouraged many of the professionals involved in the collaborative. Considering challenges facing the social work workforce such as burnout and turnover, striking comments made by professionals involved in this collaborative suggested this type of work may have an impact on one's renewed commitment to the mission of the field. Second, families acknowledged an increased respect for the professionals as they talked about seeing the struggles and barriers social workers face in a new way. Increased insight and understanding between families and professionals may help to bridge the gap of misunderstanding common in these relationships. In addition to increased respect for workers, family partners also discussed being empowered by their work on the collaborative. Several family partners suggested that being asked to serve in this capacity raised their self esteem, brought purpose to their lives and brought relationships they found meaningful. Although this study did not deliberately explore the impact of the BSCSI on participants, many of the comments from the qualitative data suggested this was an unexpected but positive finding.

\section{IMPLICATIONS}

As agencies consider collaborative efforts such as these, it may be helpful to review implications from this study. First, it is important that early communication seeks clarity for team members regarding their purpose and roles in the process. A decrease in ambiguity may have helped maintain some of the partners who left the collaborative. Particularly when people are engaged in volunteer efforts, it seems critical that they be able to see the purpose and potential benefit realized through their efforts to encourage ongoing involvement. Second, team members need to be supported by agency 
administration such that their efforts have the ability to affect change within the organization. Volunteers and professionals alike experience frustration when they face ongoing barriers to implementation of new ideas. This discouragement can undermine community efforts such as these. Therefore, increased communication and collaboration is needed between these teams and the larger social service delivery system in similar efforts that seek to improve and integrate services.

Even with improved coordination, barriers can be expected. Practical support and acknowledgement are needed to encourage teams to move forward despite the obstacles they face. Similarly, flexible yet consistent leadership is critical as the teams must negotiate diverse schedules, opinions, and needs while maintaining their commitment a common vision. Team leaders play an essential role in facilitating productive dialogue and organizing efforts so that action is taken. Finally, as collaborative efforts seek to include family members, clearly one of the hallmarks of this initiative, teams need more support in making this happen. Future research is needed to help community-based initiatives understand how to better recruit and engage family partners in such efforts.

\section{CONCLUSION}

The BSCSI provides an example of a strengths-based initiative seeking to improve social services through increased integration by creating a collaborative of 20 diverse teams coming together to dialogue about problems and solutions across these local communities. The findings from the mixed methods examination of this effort allowed the researchers to observe a complex process seeing both the challenges faced along with the ability to persevere and ultimately observe the impact for families living in these communities. Lessons learned from this initiative can be helpful to other organizations who similarly value community-based efforts to address complex problems.

\section{References}

Annie E. Casey Foundation (AECF). (2007). The Annie E. Casey 2007 Kids Count data book: State profiles of child well-being. Baltimore, MD: Author.

Blundo, R. (2001). Learning strengths-based practice: Challenging our personal and professional frames. Families in Society, 82(3), 296-304.

Boyes-Watson, C. (2005). Seeds of change: Using peacemaking circles to build a village for every child. Child Welfare, 84(2), 191-207.

Brun, C., \& Rapp, R. C. (2001). Strengths-based case management: Individuals’ perspectives on strengths and the case manager relationship. Social Work, 46(3), 278288.

Chapin, R. K. (1995). Social policy development: The strengths perspective. Social Work, 40(4), 506-514.

Cohen, B. (1999). Intervention and supervision in strengths-based social work practice. Families in Society, 80(5), 460-466. 
Colby, I. C. (1997). Transforming human services organizations through empowerment of neighbors. Journal of Community Practice, 4(2), 1-12.

Coleman, H., \& Unrau, Y. (2008). Analyzing qualitative data. In R. Grinnell \& Y. Unrau (Eds.), Social work research and evaluation ( $8^{\text {th }}$ ed., pp. 387-408). New York: Oxford Press.

Creswell, J. W. (2003). Research design: Qualitative, quantitative and mixed methods approaches $\left(2^{\text {nd }}\right.$ ed.). Thousand Oaks, CA: Sage Publications.

Deming, E. W. (1986). Out of the crisis. Cambridge, MA: Massachusetts Institute of Technology, Center for Advanced Engineering.

Dillman, D. A. (2007). Mail and internet surveys: The tailored design method. New York: John Wiley and Sons.

Early, T., \& GlenMaye, L. (2000). Valuing families: Social work practice with families from a strengths perspective. Social Work, 45(2), 118-130.

Goldstein, H. (1997). Victors or victims? In D. Saleebey (Ed.), The strengths perspective in social work practice ( ${ }^{\text {nd }}$ ed., pp. 21-35). New York: Longman.

Greene, G. J., Lee, M. Y., \& Hoffpauir, S. (2005). The languages of empowerment and strengths in clinical social work: A constructivist perspective. Families in Society, 86(2), 267-277.

Halley, A. (1997). Applications of boundary theory to the concept of service integration in the human services. Administration in Social Work, 21(3/4), 145-168.

Hassett, S., \& Austin, M. J. (1997). Service integration: Something old and something new. Administration in Social Work, 21(3/4), 9-29.

Horsburgh, D. (2003). Evaluation of qualitative research. Journal of Clinical Nursing, 12, 307-312.

Itzhaky, H., \& Bustin, E. (2002). Strengths and pathological perspectives in community social work. Journal of Community Practice, 10(3), 61-73.

Kisthardt, W. (2006). The opportunities and challenges of strengths-based, personcentered practice: Purpose, principles, and applications in a climate of system's integration. In D. Saleebey (Ed.), The strengths perspective in social work practice ( $4^{\text {th }}$ ed., pp. 171-195). Boston: Allyn \& Bacon.

Krile, J. F. (2006). The community leadership handbook: Framing ideas, building relationships, and mobilizing resources. St. Paul, MN: Fieldstone Alliance.

Leon, A. M. (1999). Family support model: Integrating service delivery in the twentyfirst century. Families in Society, 80(1), 14-24.

Lietz, C. A. (2006). Uncovering stories of family resilience: A mixed methods study of resilient families, part 2. Families in Society, 87(4), 575-582. 
O’Looney, J. (1994). Modeling collaboration and social services integration: A single state's experience with developmental and non-developmental models.

Administration in Social Work, 18(1), 61-86.

O’Looney, J. (1997). Marking progress toward service integration: Learning to use evaluation to overcome barriers. Administration in Social Work, 21(3/4), 31-65.

Padgett, D. K. (2008). Qualitative methods in social work research. Thousand Oaks, CA: Sage.

Rapp, C. A., Saleebey, D., \& Sullivan, W. P. (2005). The future of strengths-based social work. Advances in Social Work, 6(1), 79-90.

Reitan, T. C. (1998). Theories of interorganizational relations in the human services. Social Service Review, 72(3) 285-309.

Saleebey, D. (2001). The Diagnostic Strengths Manual? Social Work, 46(2), 183-188.

Saleebey, D. (2006). The strengths perspective in social work practice $\left(4^{\text {th }} \mathrm{ed}.\right)$. Boston: Allyn \& Bacon.

Sousa, L., Ribeiro, C., \& Rodrigues, S. (2006). Intervention with multi-problem poor clients: Towards a strengths-focused perspective. Journal of Social Work Practice, 20(2), 189-204.

U.S. Department of Health and Human Services, Administration on Children, Youth and Families (2007). Child maltreatment 2005.Washington, DC: U.S. Government Printing.

Waldfogel, J. (1997). The new wave of service integration. Social Service Review, 71(3), 463-484.

Weick, A., Rapp, C., Sullivan, W. P., \& Kisthardt, W. (1989). A strengths perspective for social work practice. Social Work, 34(4), 350-354.

\section{Author's note:}

Address correspondence to: Cynthia A. Lietz, School of Social Work, Arizona State University, 411 N. Central Ave, Suite 800, Phoenix, AZ, 85004-0689. Email:

clietz@asu.edu 